NASA/TM-2001-210887

AIAA-2001-1633

(1958

Impact Testing of Composites for Aircraft Engine Fan Cases

Gary D. Roberts and Duane M. Revilock

Glenn Research Center, Cleveland, Ohio

Wieslaw K. Binienda and Walter Z. Nie

University of Akron, Akron, Ohio

S. Ben Mackenzie and Kevin B. Todd

Saint-Gobain Performance Plastics, Ravenna, Ohio

Prepared for the

42nd Structures, Structural Dynamics, and Materials Conference and Exhibit cosponsored by the AIAA, ASME, ASCE, AHS, and ACS

Seattle, Washington, April 16-19, 2001

National Aeronautics and

Space Administration

Glenn Research Center 
Trade names or manufacturers' names are used in this report for identification only. This usage does not constitute an official endorsement, either expressed or implied, by the National Aeronautics and Space Administration.

Available from

NASA Center for Aerospace Information 7121 Standard Drive

Hanover, MD 21076

National Technical Information Service 5285 Port Royal Road Springfield, VA 22100

Available electronically at http://gltrs.grc.nasa.gov/GLTRS 


\title{
IMPACT TESTING OF COMPOSITES FOR AIRCRAFT ENGINE FAN CASES
}

\author{
Gary D. Roberts and Duane M. Revilock \\ National Aeronautics and Space Administration \\ Glenn Research Center \\ Cleveland, Ohio 44135 \\ Wieslaw K. Binienda and Walter Z. Nie \\ University of Akron \\ Akron, Ohio 44325 \\ S. Ben Mackenzie and Kevin B. Todd \\ Saint-Gobain (formerly Norton) Performance Plastics \\ Ravenna, Ohio
}

\begin{abstract}
Before composite materials can be considered for use in the fan case of a commercial jet engine, the performance of a composite structure under blade-out loads needs to be demonstrated. The objective of this program is to develop an efficient test and analysis method for evaluating potential composite case concepts. Ballistic impact tests were performed on laminated glass/epoxy composites in order to identify potential failure modes and to provide data for analysis. Flat $7^{\prime \prime} \mathrm{X} 7$ " panels were impacted with cylindrical titanium projectiles, and $15^{\prime \prime}$ diameter half-rings were impacted with wedge-shaped titanium projectiles. Composite failure involved local fiber fracture as well as tearing and delamination on a larger scale. A $36^{\prime \prime}$ diameter full-ring subcomponent was proposed for larger scale testing. Explicit, transient, finite element analyses were used to evaluate impact dynamics and subsequent global deformation for the proposed fullring subcomponent test. Analyses on half-ring and quarter ring configurations indicated that less expensive smaller scale tests could be used to screen potential composite concepts when evaluation of local impact damage is the primary concern.
\end{abstract}

\section{INTRODUCTION}

High-bypass-ratio turbofan engines are used to power modern large commercial aircraft because of their high overall efficiency, high thrust at low flight speeds, low jet velocity, and low fuel consumption. "The fan case is the largest structural component in these engines.

Currently, metal alloys are used for the case material in all commercial engines. Use of composite materials could significantly reduce the weight of the fan case, however technical feasibility and cost effectiveness first need to be demonstrated. The fan case in a jet engine is required to contain a fan blade in the rare event of a blade loss during engine operation. Because of the safety issues involved, full-scale demonstration of any new design is required by government regulations before the design can be used in commercial engines. This is an expensive process that has limited the development and use of new fan case materials and designs. Manufacturing cost has been a major limiting factor in the development and use of large composite structures for jet engines. However, fiber costs are projected to decrease substantially, and rapid developments are occurring in the area of low cost manufacturing of large composite structures. As a result, fabrication of a composite fan case should be economically feasible in the near future. Design of a composite case for normal engine operating conditions should also be technically feasible. However, the requirement for blade containment poses a unique challenge for the design of a composite fan case.

There are two major technical challenges for the use of composite materials in a fan case. The first is to demonstrate that a containment system with a composite case can stop a failed blade from reaching the engine nacelle. The second is to demonstrate that the case can maintain structural integrity after a bladeout incident. Structural integrity is required to limit secondary damage caused by impact debris and to constrain out-of-balance motion of the rotor after a blade or blade fragment is lost. Ultimately, the performance of a composite fan case must be demonstrated in a full-scale engine blade-out test according to Federal Aviation Regulations. ${ }^{2}$ In this test, a fan blade is released at full operating speed. Since the engine is destroyed in this test, it is usually the final test performed in the certification process for a new engine. Any changes to the design of the fan case at this stage can significantly increase cost and delay certification of the engine. These economic and schedule issues create tremendous pressure on the engine manufacturer to use 
traditional materials and designs. However, as engine design moves toward higher bypass ratios, there will be an increasing need to consider composite materials for the larger diameter fan cases.

Explicit finite element analysis is beginning to be used earlier in the design cycle for metal fan cases to shorten development time, reduce testing cost, and reduce the risk of failure for the final design. This approach is also used in the automobile industry where explicit finite element analysis is used in conjunction with instrumented crash tests to improve vehicle crashworthiness. Recent advances in the use of explicit codes such as LsDyna3D and ABAQUS/Explicit allow numerical testing of an entire car before even a single car body is manufactured. A similar approach is needed to overcome the large development cost and technical risk associated with using a new composite fan case design. Use of finite element analysis to assist design is most effective when a design methodology already exists and a large database (laboratory tests, certification tests, and field service) is available for validation. This is a particularly important issue for composites because of the large number of possibilities for fiber orientation, failure mode, materials, and manufacturing method. Unfortunately, there is no prior certification or service experience for a composite case, and only a limited amount of laboratory data is available from government and commercial technology development programs.

The two main goals of this work are: (1) to develop and demonstrate design concepts for a composite fan case and (2) to generate test data and analysis methods for future use as part of an overall design methodology. The first step is to evaluate the capabilities and limitations of current materials, test methods, and explicit finite element analysis methods. In this paper, ballistic impact test results are reported for composite panels. A larger full-ring structure is proposed as a possible subcomponent design. Explicit finite element analysis is used to evaluate impact dynamics for the proposed subcomponent test.

\section{COMPOSITE IMPACT TESTS}

Ballistic impact tests have been used on targets ranging in size from small flat panels to full-scale subcomponents. Full-scale tests can simulate many of the conditions in a real blade-out incident. Small panel tests attempt to simulate at least a few critical parameters. The impact velocity is usually chosen as the center of mass velocity of the blade fragment. The projectile shape and orientation relative to the target is determined from the blade dynamics and the type of damage observed in the case. This information must be obtained from full-scale testing and analysis since it depends on the particular engine design and operating conditions. The design of the fan containment system in a particular engine depends on issues such as weight, cost, prior experience, and limitations on space available for case deflection. Two design approaches are currently used for blade containment. In the "hardwall" design, the wall thickness near the blade impact site is made sufficiently thick to resist penetration, and ribs are used to control global stiffness. In this design, local damage at the impact site must be minimized, and propagation of the damage must be limited so that global stiffness and strength of the structure are maintained. In the "softwall" design, the metal case is penetrated by the blade and captured by an outer wrap of fabric. In this design, stiffness is provided by either an isogrid or honeycomb structure on the case. Although the blade is allowed to penetrate the case in the softwall design, it is critical that the perforated area be kept as small as possible and that the damaged area does not grow to affect global stiffness and strength.

The high specific stiffness and low density of composites are advantages for both hardwall and softwall designs, but poor impact resistance is a potential problem. Low velocity impact of composites can cause extensive internal damage (microcracking, delamination) with little visible surface damage. ${ }^{3}$ High velocity tests on composites using flat, hemispherical, and conical projectiles have shown shear failure in plies nearest the impact surface to be the initial failure mode. ${ }^{4}$ Subsequent damage modes depend on the materials, fiber architecture, and ply lay-ups, but often include delamination and fiber tensile failure in the interior or near the back surface plies.

In order to identify expected damage modes under simulated blade-out conditions, a $15^{\prime \prime}$ diameter, $0.420^{\prime \prime}$ thick 2D laminated glass/epoxy half ring was impacted with a wedge-shaped titanium projectile at a velocity of $850 \mathrm{ft} / \mathrm{s}$. The $0.73 \mathrm{lb}(330 \mathrm{~g})$ wedge was $5^{\prime \prime}$ long by $3.75^{\prime \prime}$ wide with the thickness increasing from $1 / 8^{\prime \prime}$ at the thin edge to $3 / 8^{\prime \prime}$ at the thick edge to simulate the mass distribution of a fan blade fragment. To simulate the blade dynamics, the desired orientation of the wedge was $45^{\circ}$ from the horizontal with the thin edge of the wedge making contact first. The thin edge curls after contact as the wedge rotates and the thick edge makes a second contact. Figure 1 shows the wedge and a side view of the $15^{\prime \prime}$ half-ring after impact. Local fiber shear fracture occurs along the lines where the thin and the thick edges of the wedge make contact. Extensive delamination occurs throughout the composite, and tearing occurs in plies near the back surface. Damage also appears to be concentrated at some points around 
the edges where the panel was held in place by the metal fixtures.

The damage evident in Figure 1 indicates that a composite hardwall containment system will require use of a surface layer that is capable of eliminating local shear failure. In addition, some method for controlling delamination will be needed. Lightweight materials and structures that are capable of absorbing a large amount of energy have been developed for armor applications. Although most of these materials are not suitable for use as the main structural material in a containment case, a recent report ${ }^{5}$ has examined the feasibility of applying some of these armor concepts to commercial aircraft in the form of protective barriers that could enhance aircraft survivability in the event of an uncontained engine failure. One such concept is to place a ceramic plate on the impact surface of the composite. The ceramic serves to fragment the projectile and spread the impact load over a larger area of the backing plate. Projectile fragmentation occurs at very high impact velocities as a result of shock waves within the projectile. This process is unlikely to occur with large titanium blade fragments impacting a case at velocities characteristic of a blade-out event. However, a ceramic layer may still be useful for spreading the impact load and blunting sharp blade fragments. Delamination can be controlled by reinforcement in the transverse direction by processes such as stitching, pinning, or 3D weaving. Evaluation of these concepts using the test configuration shown in Figure 1 would be expensive and time consuming. The high cost is a result of fabrication costs for the panels, fabrication costs for the projectile, and the cost of performing the test. Although the proposed concepts would not necessarily be too expensive for commercial production, fabrication of a small number of test panels can be very costly. For example, set-up costs for weaving represent a small part of the total cost for a large production run but a large part of the cost for fabrication of a small number of panels. In addition, scheduling such a small run often cannot be done in a timely manner. The wedge used for the test shown in Figure 1 requires machining of a block of titanium. A simpler projectile that could be cut from stock material would be less expensive and more readily available. In addition, the impact test shown in Figure 1 is somewhat complex. Since the projectile is not cylindrical or spherical, it must be mounted in a cylindrical container (sabot) in order to fit into the barrel of the gas gun. The $45^{\circ}$ pitch angle is achieved by bonding the titanium wedge to a $45^{\circ}$ prism-shaped wood platform within the sabot. Imprints of the wedge in the test panel and high-speed video of the projectile during the test have shown that the orientation of the wedge often deviates in pitch and roll from the desired orientation. Deviations in the location of impact can also cause variability in the results. The location and orientation of the blade has a large effect on the damage induce by impact. Damage induced by the first contact of the thin edge of the wedge is more severe for pitch angles less than $45^{\circ}$. Rotation of the wedge also causes more severe damage because the wedge makes contact at its corners rather than along its edges. All of these factors indicate that a simpler, less expensive test would be preferable for preliminary screening of composite concepts. In this paper, a simpler test was used to evaluate the performance of a ceramic layer on a glass/epoxy composite and the performance of $3 \mathrm{D}$ woven materials. Some justification based on observed failure modes is discussed below. Analysis of impact dynamics for a full-ring structure, discussed in a later section, provides further support for the use of the simpler test method.

Small $\left(7^{\prime \prime} \mathrm{X} 7^{\prime \prime}\right)$ flat panels were impacted with flatended cylindrical titanium projectiles $(2.54 \mathrm{~cm}$ long, $1.27 \mathrm{~cm}$ diameter). Panel and projectile shapes are shown in Figure 2. This test is less realistic than tests with the wedge-shaped projectile in the sense that it cannot simulate blade dynamics. However, preliminary tests on laminated composite panels with various fiber and matrix materials demonstrated that the impact damage had features similar to those shown in Figure 1. Fiber shear fracture occurred on the front surface, delamination occurred in the interior, and fiber tearing occurred on the back surface. The ballistic limit was determined by testing approximately $6-8$ panels over a range of impact velocities. Ideally, the ballistic limit is the velocity below which the projectile does not perforate the panel and above which the projectile completely perforates the panel. The ballistic limit can then be defined as the average of the highest velocity that did not perforate and the lowest velocity that completely perforated the panels. In practice, there may be a small velocity region near the ballistic limit in which non-perforation and perforation overlap. In addition, failure may be defined by a criterion other than complete perforation. For example, a plate may be considered to fail the test if a crack propagates through the panel, even though the projectile does not perforate the panel. The above definition for ballistic limit can still be used, as long as the failure criterion is defined.

Impact test data for five different types of composite panels are shown in Figure 3. For these composite panels there was a velocity region near the ballistic limit within which the projectile was caught in the panel. This was interpreted as perforation (or failure) for the purpose of calculating the ballistic limit. The ballistic limits calculated from the data in Figure 3 are shown in Figure 4 along with the ballistic limits that have been measured for 304 stainless steel and for 
Inconel 718. The stainless steel alloy was chosen for comparison because it has been used in commercial fan cases. The ballistic limits of Inconel 718 in the annealed and heat treated forms are shown to indicate the range of properties possible for some alloys by heat treatment. The thickness (or areal weight) range of the metal alloy panels used to obtain the data in Figure 4 was chosen so that the ballistic limits would fall within the range of velocities which are characteristic of blade fragments during a blade-out. It is useful to have data over a range of areal weights because it is usually not feasible to fabricate panels of different materials with exactly equal areal weights for direct comparison.

The first composite concept evaluated was the use of a $1.9 \mathrm{~mm}\left(0.075^{\prime \prime}\right)$ thick silicon carbide ceramic layer to reduce the extent of shear failure at the impact surface. $7 " \mathrm{X} 7^{\prime \prime}$ glass/epoxy panels were cut from a larger $16.5^{\prime \prime} \times 38.0^{\prime \prime}$ panel that was made by hand lay-up of 28 plies of type 6781 S2 glass/E-761 epoxy prepreg with autoclave cure. Six of the $7^{\prime \prime} X 7^{\prime \prime}$ panels were used to measure the ballistic limit of the composite (Figure 3). In Figure 4, the ballistic limit of the S2 glass/E-761 composite is $191 \mathrm{~m} / \mathrm{s}(626 \mathrm{ft} / \mathrm{s})$, which is well below that of the metal alloys at an equivalent areal weight. Figures $2 a$ and $2 b$ show the front and back surfaces after impact for glass/epoxy panels with and without a ceramic front layer. The lower panel in Figure 2a has a nylon spall sheet bonded to the surface to catch ceramic fragments during the test. The ceramic fragments have been removed to view the surface of the composite. The panels in Figure 2 were impacted at $636 \mathrm{ft} / \mathrm{s}(194 \mathrm{~m} / \mathrm{s})$, just above the ballistic limit. The panel without the ceramic layer exhibited the typical failure modes of fiber shear failure on the front, delamination in the middle plies, and tearing on the back. The ceramic layer completely eliminated the fiber shear fracture on the front surface but did not reduce the extent of delamination as viewed from the back side of the panels. The dashed circles in Figure $2 b$ show the delamination areas visible from the back side of the panels. (Delamination is clearly visible when viewing the panels but does not show well in the photographs). Although the ceramic layer is effective in eliminating fiber shear failure at the impact surface, this benefit comes at the expense of increasing the areal weight of the panel. Further tests are needed to determine the optimum ceramic thickness and the effectiveness of the ceramic on a total areal weight basis.

The second concept evaluated was use of a 3D woven architecture to reduce delamination. Composites were fabricated using $3 \mathrm{D}$ carbon fiber preforms and resin transfer molding. The main system of interest was IM7 fiber with the toughened epoxy resin, PR520. However, options were also considered for potential cost reduction. For material cost reduction, E-862 epoxy resin was used in place of PR520, and AS4 fiber was used in place of IM7. For weaving cost reduction, tows of the AS4 fiber were combined during weaving. This resulted in a courser weave for the AS4/PR520 and AS4/E-862 composites compared to the IM7/PR520 and IM7/E-862 composites. Failure on the front surface of the 3D woven composites was similar to that of the 2D glass/epoxy laminated composites with local shear failure on the front surface. However, the subsequent damage pattern was different. For the 3D composites there was no evidence of delamination, but there was a region of microcracking around the impact site, particularly for the more brittle E-862 resin. The 3D composites had fiber breakage but no ply tearing on the back side. The IM7/PR520 composite had a ballistic limit of $190 \mathrm{~m} / \mathrm{s}(623 \mathrm{ft} / \mathrm{s})$, comparable to that of the heat-treated Inconel 718 at an equivalent areal weight. The ballistic limit of the IM7/E-862 composite was lower at $179 \mathrm{~m} / \mathrm{s}(587 \mathrm{ft} / \mathrm{s})$. Ballistic limits for composites made using the courser weave and AS4 fibers were $156 \mathrm{~m} / \mathrm{s}(512 \mathrm{ft} / \mathrm{s})$ for AS4/PR520 and $159 \mathrm{~m} / \mathrm{s}(522 \mathrm{ft} / \mathrm{s})$ for AS4/E-862. This is much lower than the ballistic limits of the metal alloys in Figure 4. The IM7 composites exhibited a slight permanent conical deformation in the impact region when tested near the ballistic limit. This type of permanent deformation is typical for metal alloys but not for composites. This effect occurred to a much smaller extent in the AS4 composites and not at all in the 2D laminated glass/epoxy composites.

\section{SUBCOMPONENT DEFINITION}

Although more small panel testing is needed to optimize performance, there are three results from the small panel tests that indicate scale-up is justified. First, the ballistic limit of some composites approaches that of the metals, even though the materials and fiber architecture have not yet been optimized. Second, transverse fiber reinforcement is effective in limiting delamination. Third, the ceramic layer is effective in eliminating fiber shear failure at the impact surface. The next level of testing should address the issues of manufacturability and cost as well as demonstrating technical feasibility at a larger scale. The subcomponent test in Figure 5 is proposed for this purpose. The $36^{\prime \prime}$ diameter ring will be manufactured by filament winding. Filament winding is a low cost process for fabricating cylindrical structures. This process also allows for considerable flexibility in materials selection and fiber architecture. In addition, features such as ribs and flanges can be included in the design. If the composite material properties are not strain rate dependent, scaling of displacement, contact forces, and strains from a small test to a larger prototype is 
possible, but scaling of damage is not. ${ }^{6}$ Therefore, results of the small panel tests can be used as a guide to the design of the subcomponent in Figure 5, but some preliminary testing and development of a numerical model will be needed to implement a cost effective test program at this larger scale.

\section{FINITE ELEMENT ANALYSIS}

Explicit, transient, finite element analysis of the proposed subcomponent in Figure 5 was performed using the commercial code ABAQUS/Explicit. ${ }^{7} \mathrm{~A}$ preliminary analysis was performed to examine the overall dynamics of the ring during and after impact. In this analysis the impact velocity was $600 \mathrm{ft} / \mathrm{s}$ and the composite ring was taken to be $0.3^{\prime \prime}$ thick with the following properties, which are representative of a glass/epoxy laminate with a $0^{\circ} / 90^{\circ}$ layup.

$E_{11}=E_{22}=2.5 \times 10^{6} \mathrm{lbf} / \mathrm{in}^{2}$

$\mathrm{G}_{12}=1.0 \times 10^{6} \mathrm{lbf} / \mathrm{in}^{2}$

$\mathrm{G}_{13}=\mathrm{G}_{23}=6.0 \times 10^{5} \mathrm{lbf} / \mathrm{in}^{2}$

$v 12=v 21=0.14$

Linear elastic, rate independent properties were used, and damage was not considered for this preliminary analysis. The projectile was a flat circular cylinder with diameter of $4.5^{\prime \prime}$, thickness of $0.75^{\prime \prime}$, and mass of $1.9 \mathrm{lb}$. It was modeled as a rigid body with a density of $0.0004086 \mathrm{lbf}^{2} / \mathrm{in}^{4}$. The ring was inclined at an angle of $22^{\circ}$ to the horizontal. The mesh in Figure 6 along with the symmetry condition about the mid plane was used for the full-ring analysis. Half-ring and quarter-ring structures with both free and fixed boundary conditions were also analyzed. Four-node thin shell S4R elements were used for the shell. Six-node and eight-node solid C3D6 and C3D8R elements were used for the projectile.

Deformation of the full ring structure at various time intervals is shown in Figure 7. At $0.11 \mathrm{~ms}$ the case begins to bulge as the top edge of the projectile pushes on the case. At $0.31 \mathrm{~ms}$ the center of the case bulges as the center of mass of the projectile contacts and pushes on the case. At later times the projectile rebounds, and a flexural wave begins to travel around the case. The displacement and velocity of the upper point on the projectile are shown in Figures $8 \mathrm{a}$ and $8 \mathrm{~b}$ for the fullring model along with the results for the half- and quarter-models with both free and fixed boundary conditions. In the time interval from 0 to $0.25 \mathrm{~ms}$, contact between the upper point on the projectile and the case causes the case to bulge and causes the projectile to slow down and rotate. Between $.25 \mathrm{~ms}$ and $0.7 \mathrm{~ms}$ the center point of the projectile contacts the case and causes the case to bulge further. This causes the velocity of the upper point on the projectile to increase during this time interval. Between $0.7 \mathrm{~ms}$ and $1.0 \mathrm{~ms}$ the projectile rebounds from the case. After $1.0 \mathrm{~ms}$ the projectile releases from the case and continues to travel at constant velocity. In the time interval from 0 to $1.0 \mathrm{~ms}$, while the projectile is in contact with the case, the motion of the projectile is very similar for the fullring and the half-rings with both free and fixed boundary conditions. The motion of the projectile impacting the quarter-rings deviates from the half- and full-ring configurations after $0.4 \mathrm{~ms}$ when the initial impact of the upper point on the projectile with the case is complete. The same conclusions result when displacements and velocities for points on the rings are analyzed. These results suggest that a half-ring configuration could be used in place of a full ring to evaluate local damage. Either free or fixed boundary conditions could be used. Alternatively, two impact tests could be performed $180^{\circ}$ apart on the same fullring. Either approach would reduce test costs. A quarter-ring configuration could be used if the purpose of the test is to evaluate local damage caused by a single impact with no subsequent complex motion of the projectile. This supports the use of a simple projectile and smaller panels for initial screening studies when local damage is the primary concern.

Strain energies stored in arcs of various sizes around the impact point are shown in Figure 9a for the full-ring configuration. The total energy (strain energy + kinetic energy) is shown in Figure 9b. An additional curve showing the energy in the full-ring plus the energy in the projectile is shown in each figure. Since the projectile is modeled as a rigid body, all of its energy is in the form of kinetic energy. In Figure 9a the strain energy grows to a maximum value at about $0.45 \mathrm{~ms}$ as the projectile comes into contact with the ring. The maximum strain energy is a little over half of the initial kinetic energy of the projectile. In Figure $9 b$ the total energy in the full-ring remains constant after about $1.0 \mathrm{~ms}$ because the projectile has rebounded from the ring. The maximum strain energy density in the ring is a useful parameter for preliminary design of the ring. From Figure 9a it appears that the maximum strain energy density would occur at about $0.40 \mathrm{~ms}$ within a $50^{\circ}$ arc. This energy density could be used in a static composite analysis to determine how close the ring is to its ultimate strength. A static analysis could also be used to suggest changes in materials, fiber architecture, or other parameters that would improve performance. The static analysis could also be used interactively with the filament winding design and machine control software to identify structures that will perform well but also be feasible to fabricate. Future efforts will focus on refining the finite element methods to model damage more precisely and include strain rate dependence. 
Efforts will also continue to refine the subcomponent design.

\section{CONCLUSIONS}

Preliminary explicit finite element analyses suggest that small panel tests can be a cost effective way to evaluate local impact resistance of a composite at the first point of contact with the projectile. Results of impact tests on $7^{\prime \prime} X 7^{\prime \prime}$ panels indicate that the ballistic limit of composites can approach that of metals. A protective ceramic surface layer is a promising approach for preventing fiber shear failure on the impact surface but not for limiting delamination. Transverse fiber reinforcement can be used to control delamination during impact. Use of a proposed $36^{\prime \prime}$ diameter full-ring subcomponent manufactured by filament winding is a reasonable approach for assessing both technical and economic feasibility of composite concepts at a larger scale than the small panel tests. Small panel testing, finite element analysis, static analysis, and preliminary design analysis using filament winding software can be integrated to reduce the time and expense of testing larger subcomponents.

\section{REFERENCES}

1. Jack D. Mattingly, "Elements of Gas Turbine Propulsion", pp xlviii-xlix, McGraw-Hill, Inc., 1996.

2. Federal Aviation Regulations Part 33.94. U.S. Federal Aviation Administration

3. Greszczuk, L.B., "Damage in Composite Materials due to Low Velocity Impact", Impact Dynamics, Chapter 3, John Wiley \& Sons, Inc. (1982), p93.

4. R.A.W. Mines, A.M. Roach, and N. Jones, "High Velocity Perforation of Polymer Composite Laminates", Int. J. Impact Eng. 22 (1999) 561-588.

5. U.S. Department of Transportation/Federal Aviation Administration Report No. DOT/FAA/AR-97/53, September 1997.

6. Abrate, Serge, "Impact on Composite Structures", pp 132-4, Cambridge University Press, 1998.

7. ABAQUS/ Explicit 5.8, Habbitt, Karlsson \& Sorensen, Inc. 


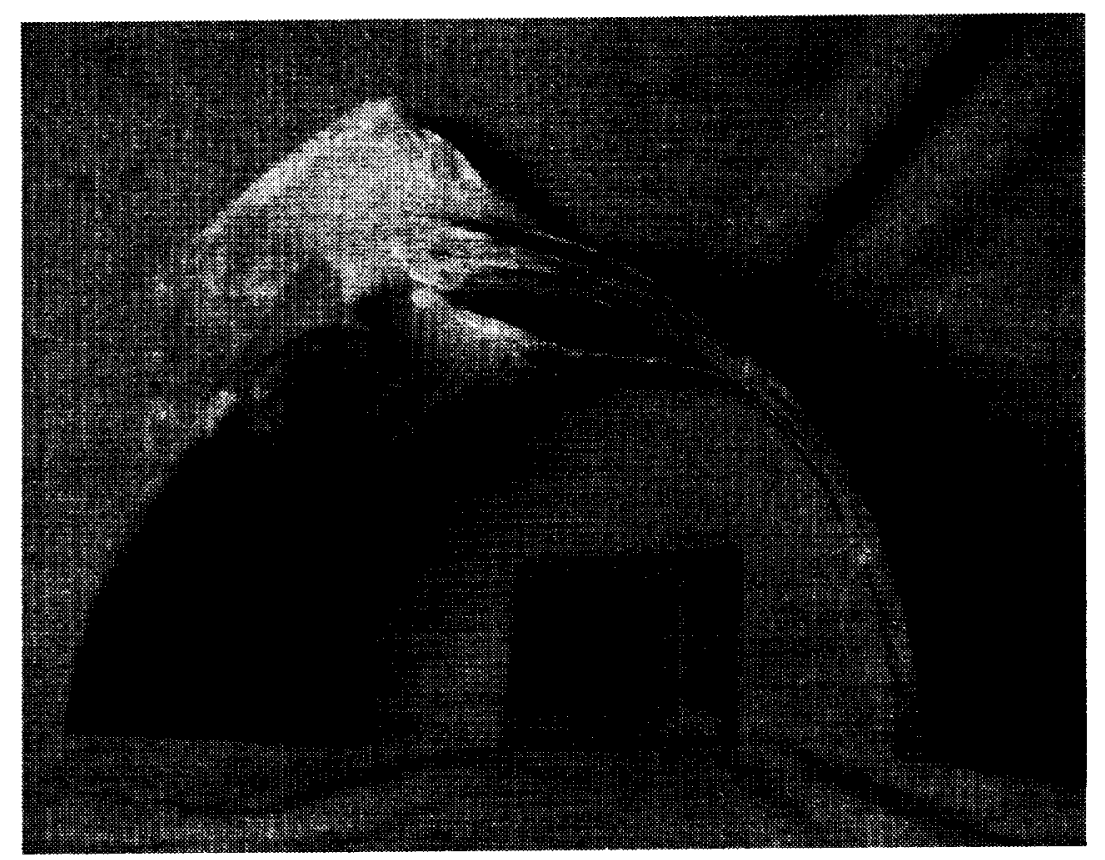

Figure 1. Glass/epoxy 15" diameter half-ring and wedge-shaped titanium projectile

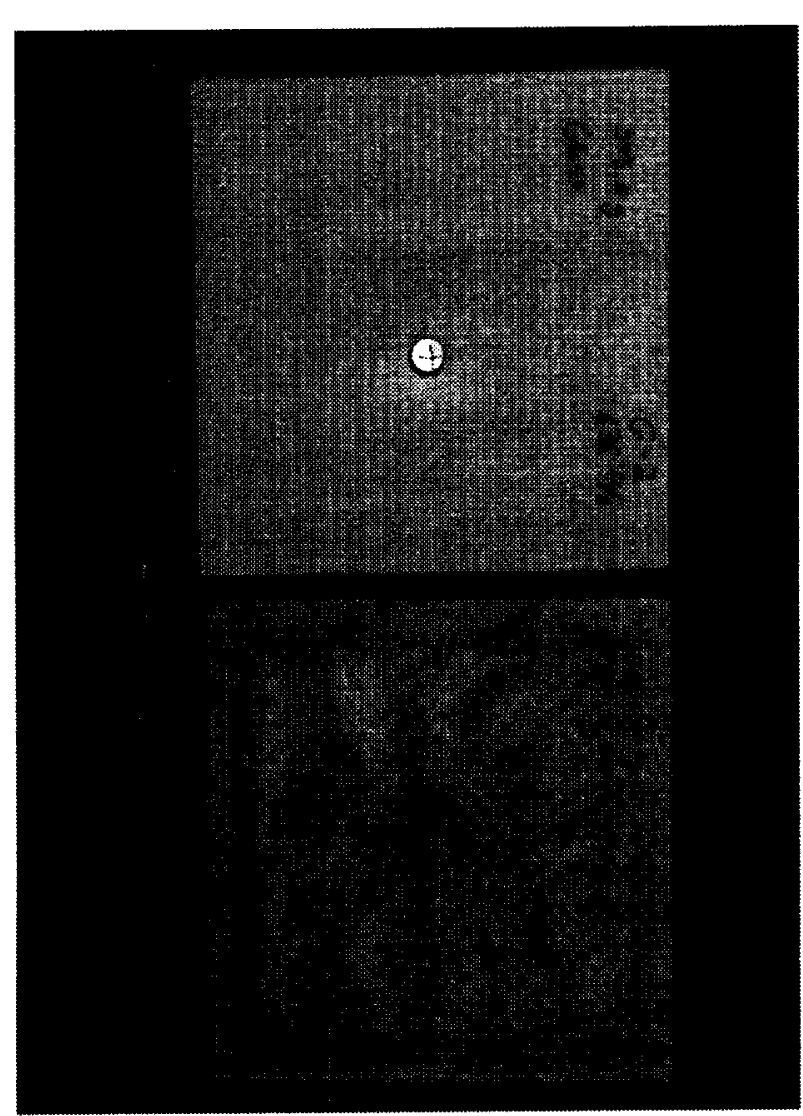

(a) Front surface

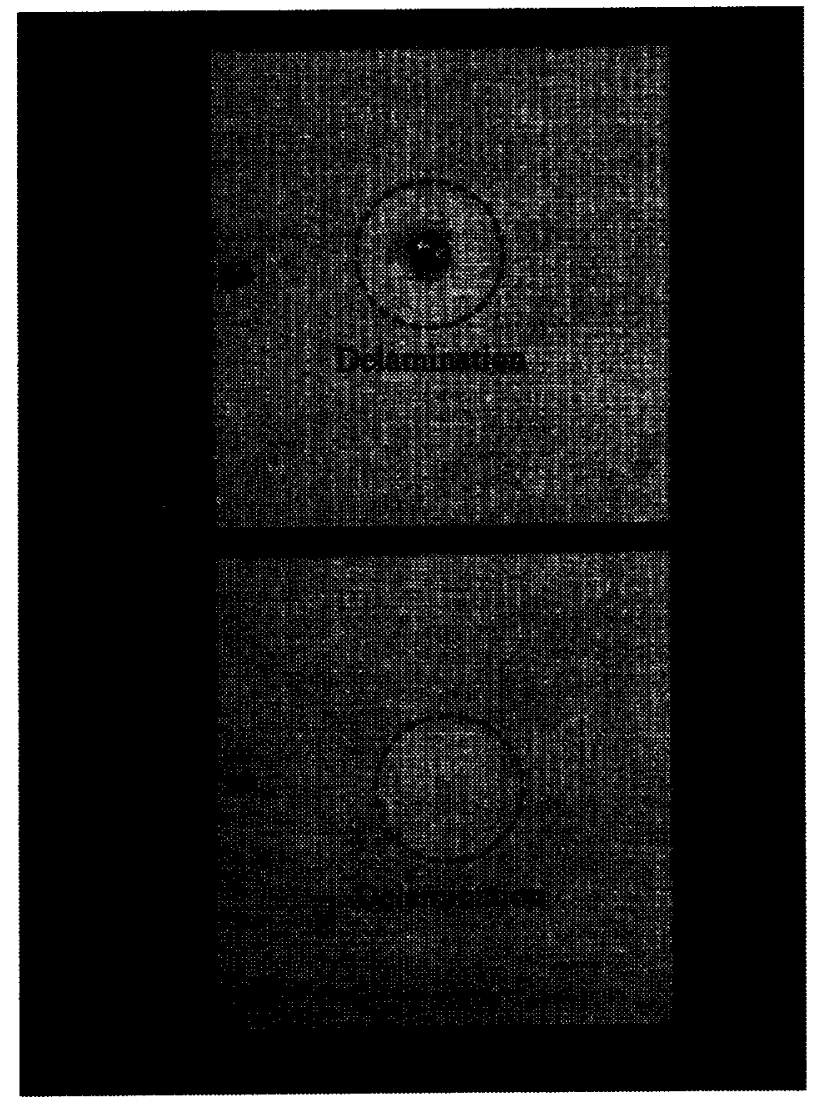

(b) Back surface

Figure 2. Glass/epoxy 7"X7" panels and cylindrical titanium projectile. Bottom panel had a ceramic layer under a nylon spall sheet on the front surface. Ceramic is removed to view the surface of the composite. 


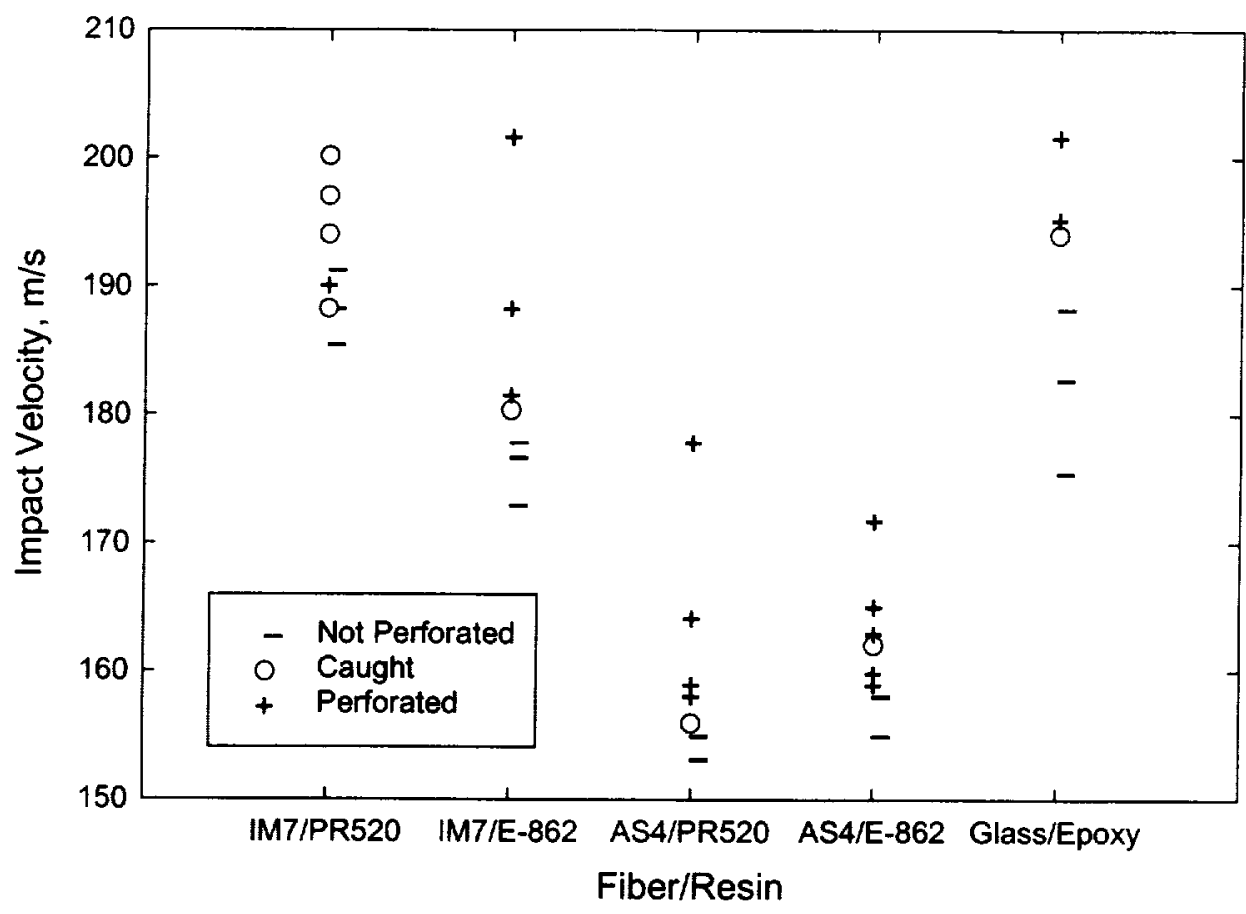

Figure 3. Composite impact test data from 7"X7" flat panel tests.

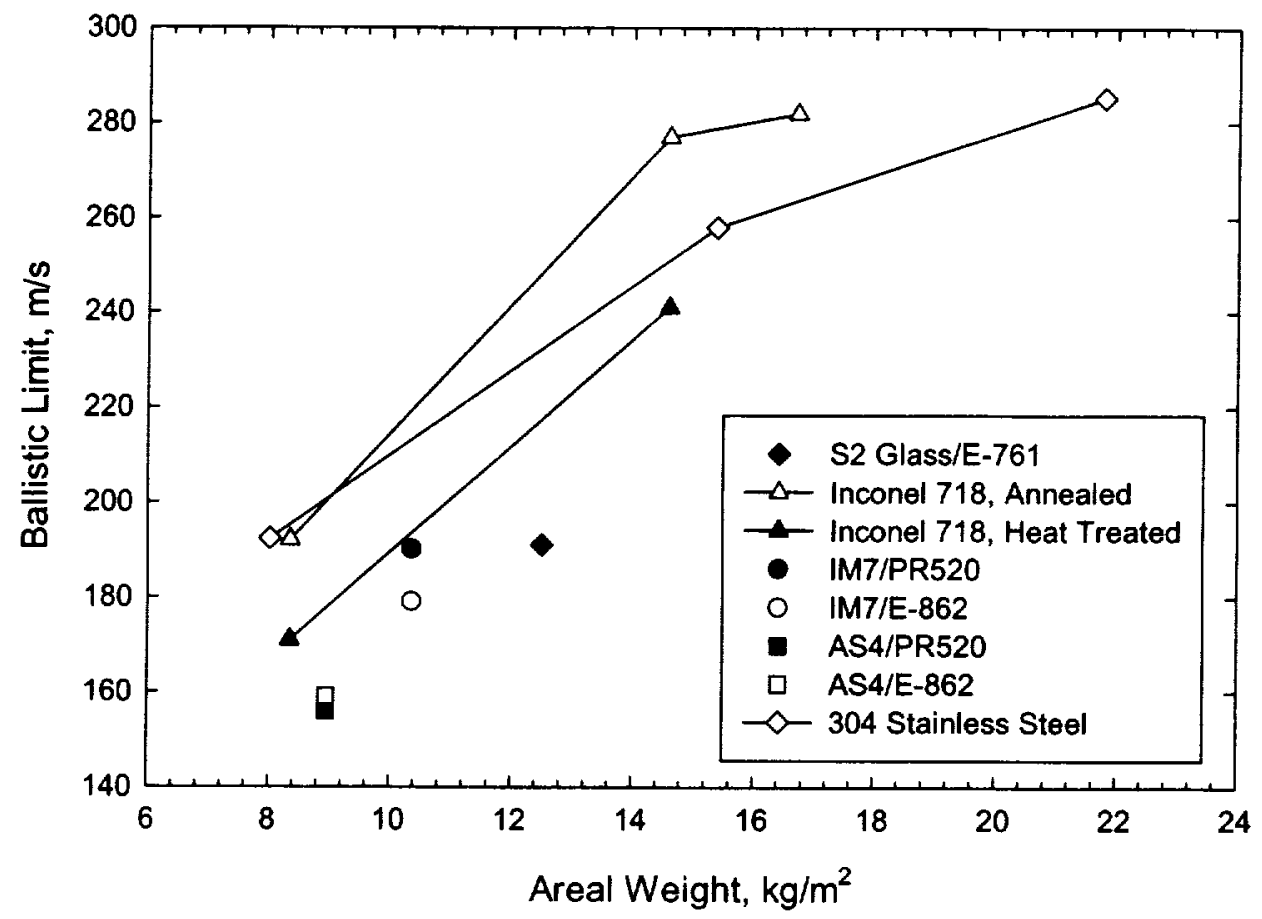

Figure 4. Ballistic limit for various composites and metal alloys. 


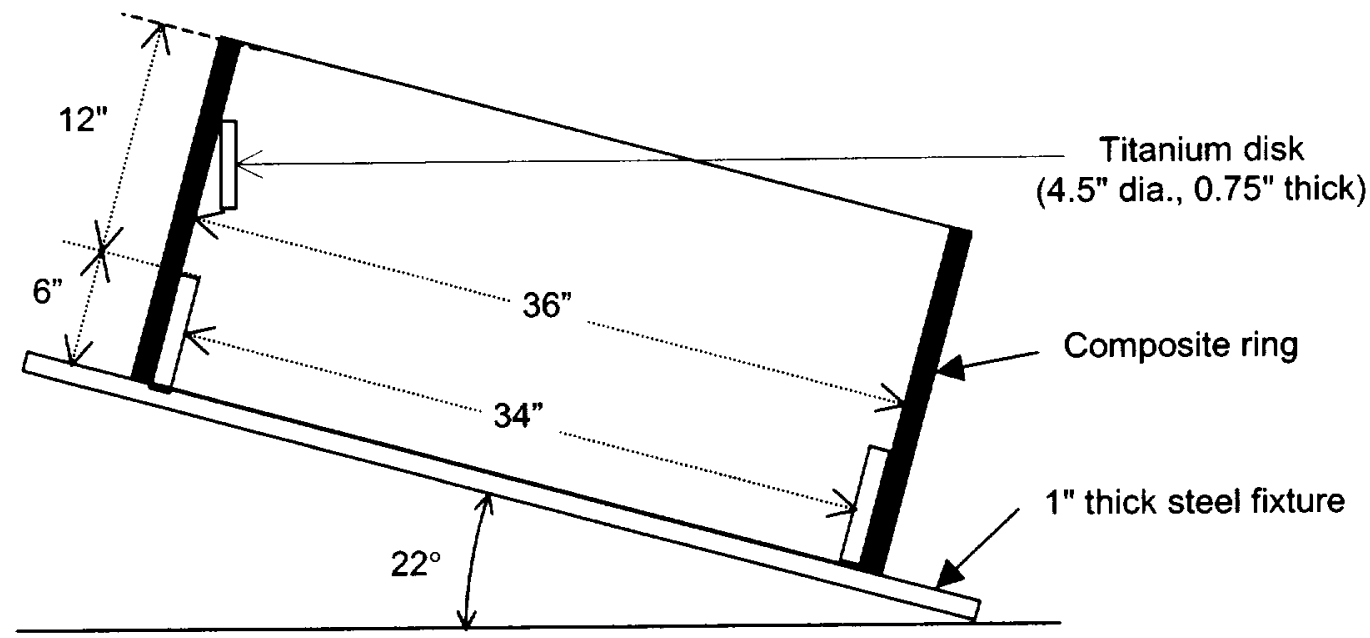

Figure 5. 36" diameter full-ring subcomponent test.
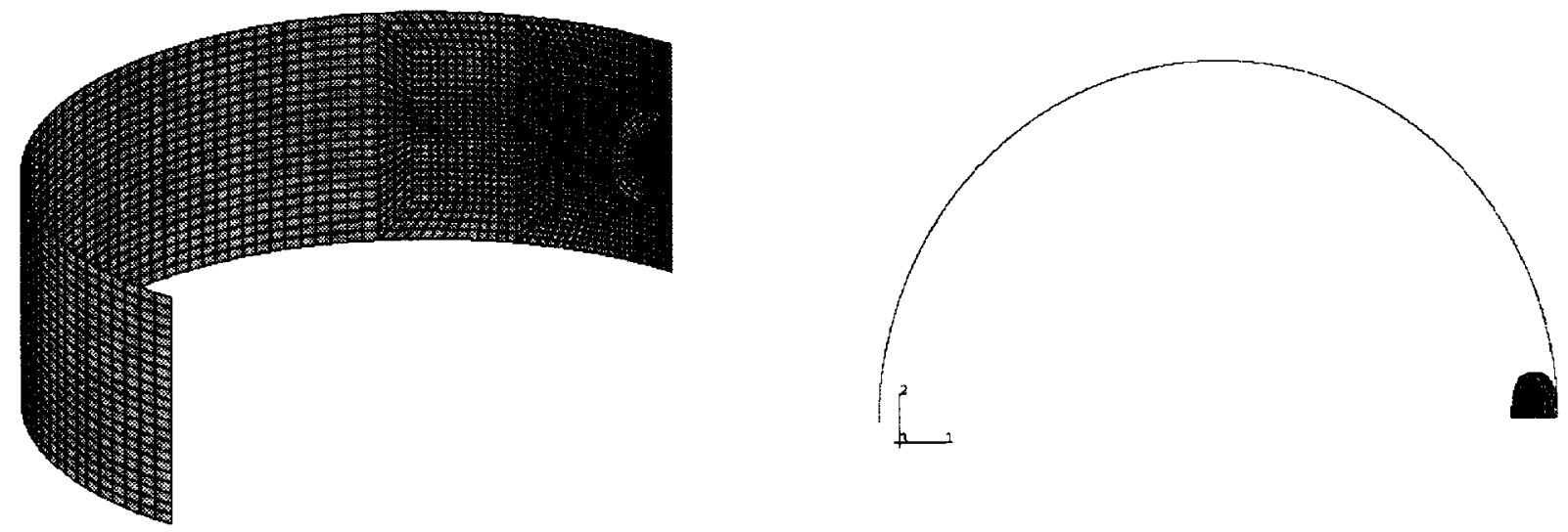

Figure 6. Finite element mesh for 36" diameter full-ring subcomponent.

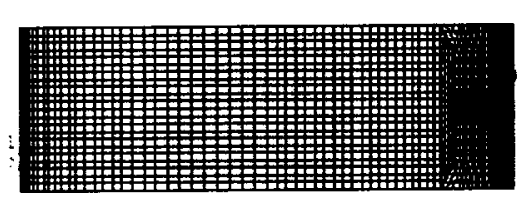

$t=0.02 \mathrm{~ms}$

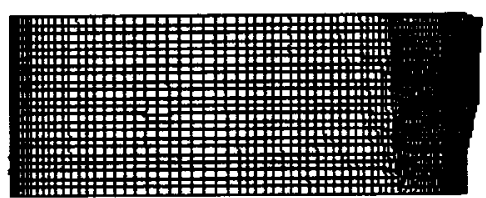

$\mathrm{t}=0.80 \mathrm{~ms}$

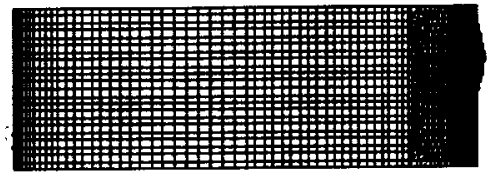

$\mathrm{t}=0.11 \mathrm{~ms}$

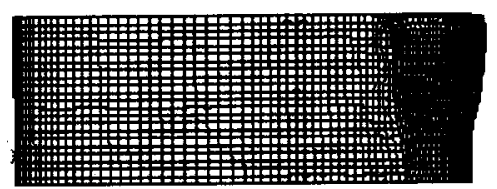

$\mathrm{t}=1.00 \mathrm{~ms}$

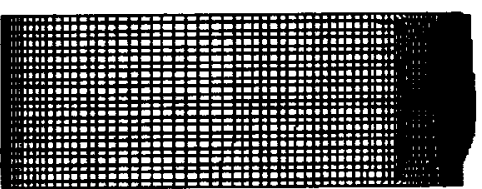

$t=0.31 \mathrm{~ms}$

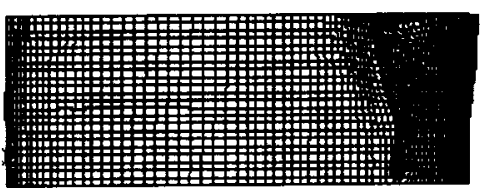

$\mathrm{t}=2.50 \mathrm{~ms}$

Figure 7. Deformation of 36 " full-ring subcomponent at various times after impact. 


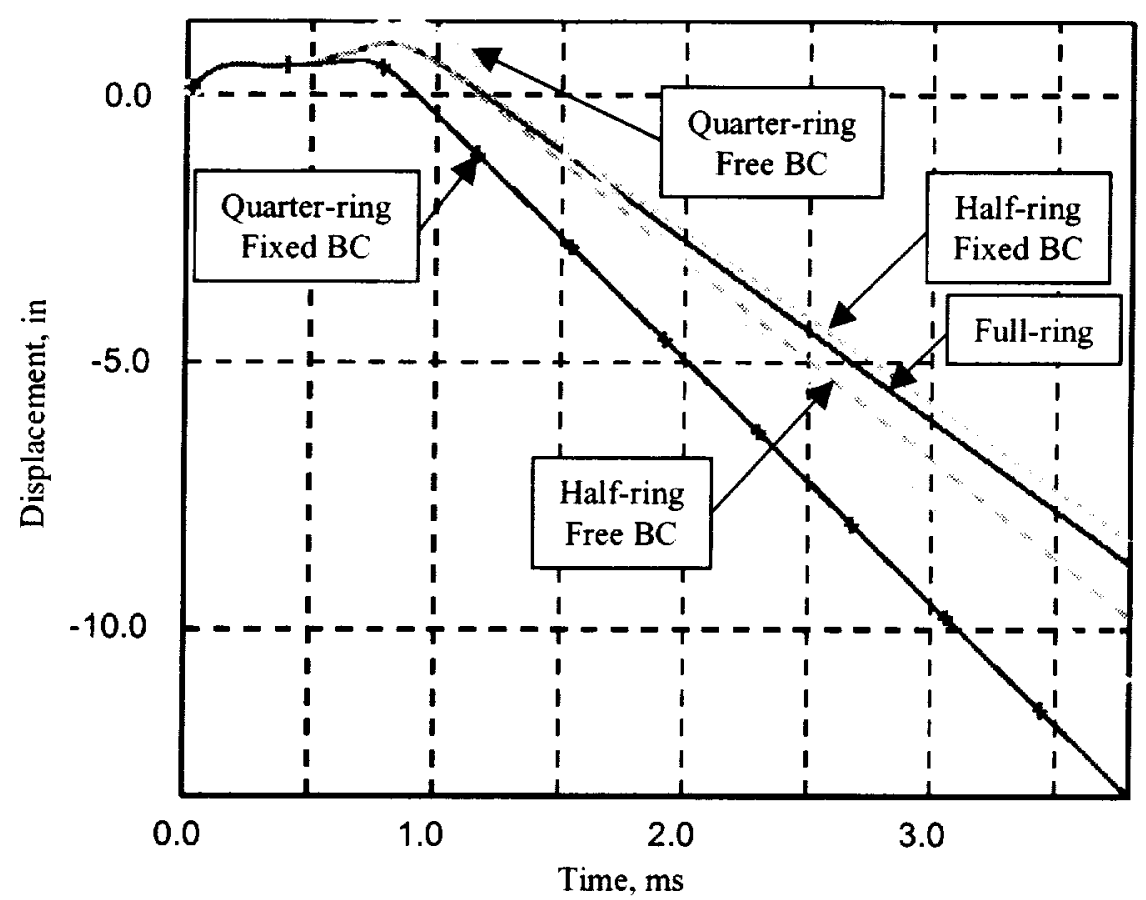

(a) Displacement of upper point on the projectile

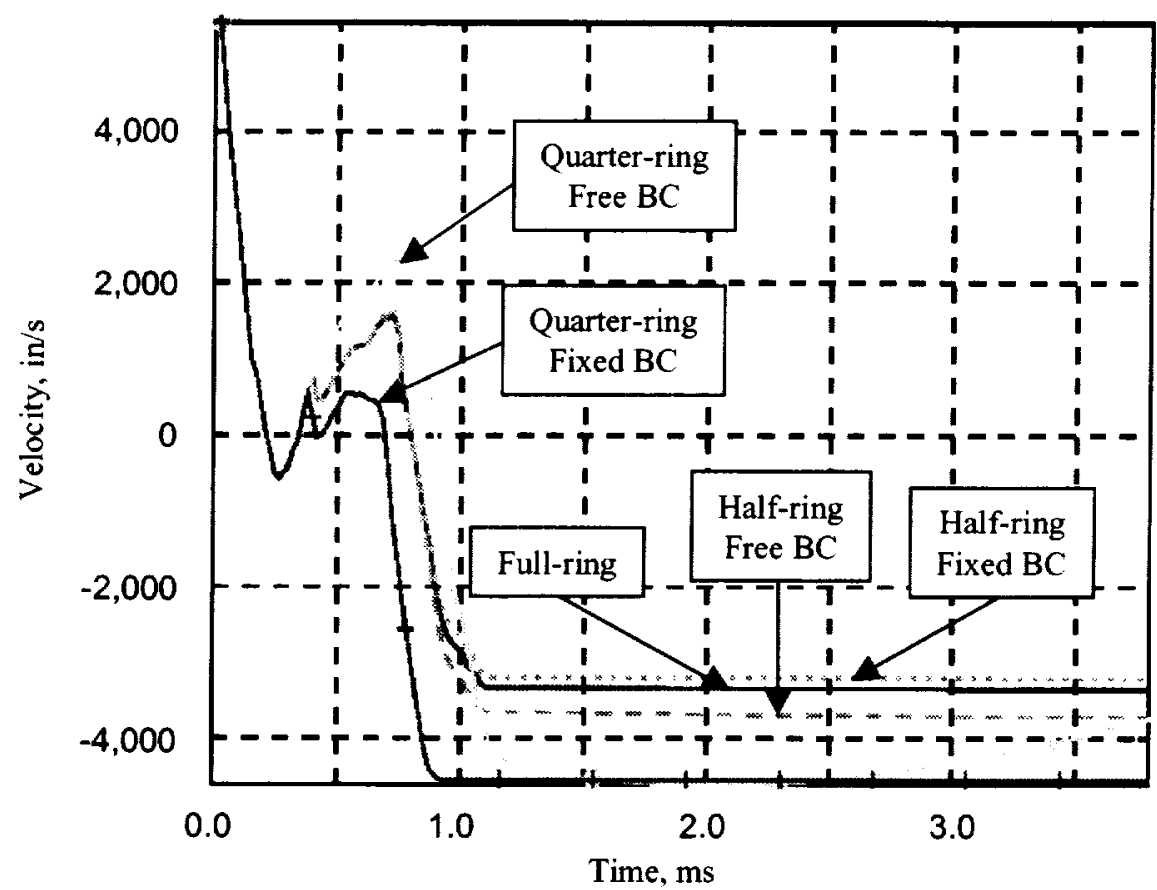

(b) Velocity of upper point on the projectile

Figure 8. Finite element analysis results for a titanium disk projectile impacting full-ring, half-ring and quarter-ring composite structures at $600 \mathrm{ft} / \mathrm{s}$. Free and fixed boundary conditions (BC) were used for half- and quarter-rings. (a) Displacement and (b) velocity of the upper point on the projectile. 


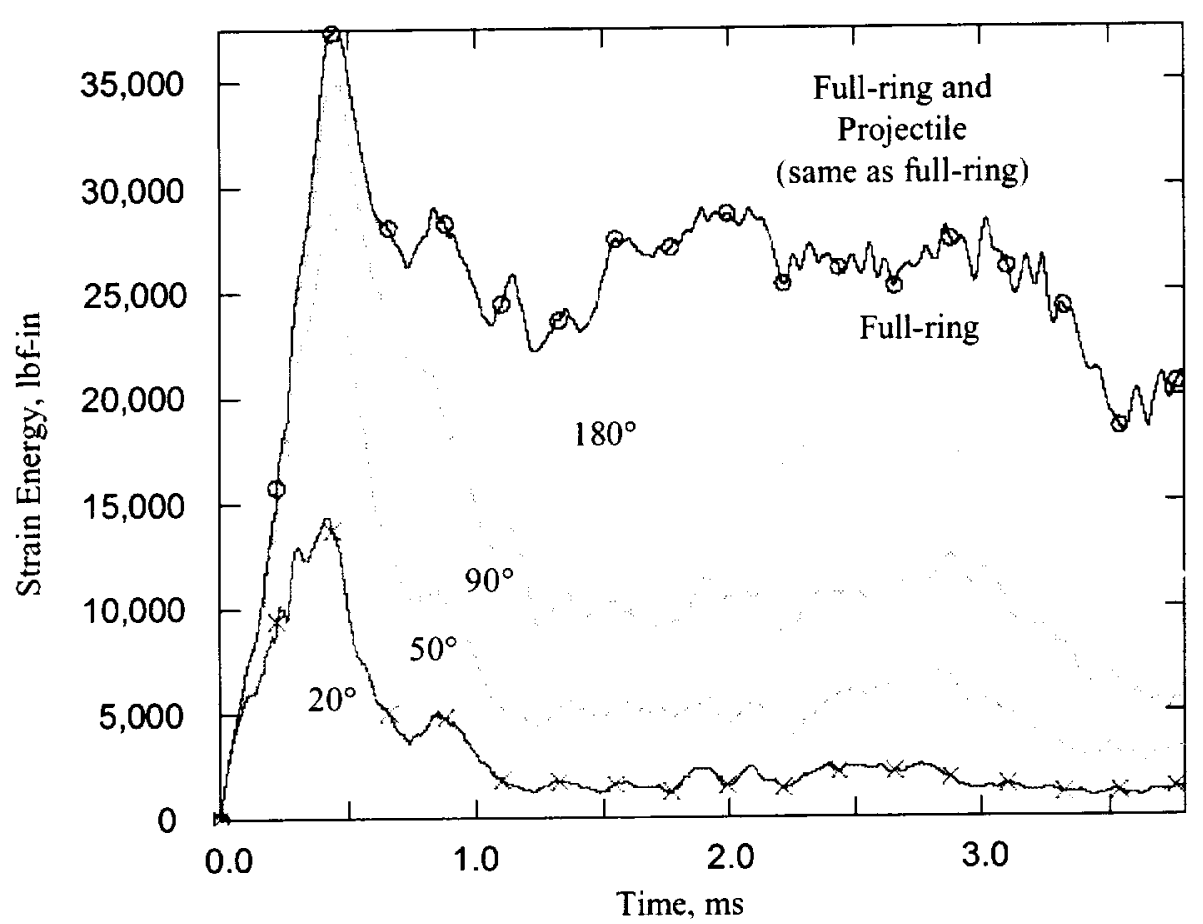

(a) Strain energy in various arc sections centered on the point of impact

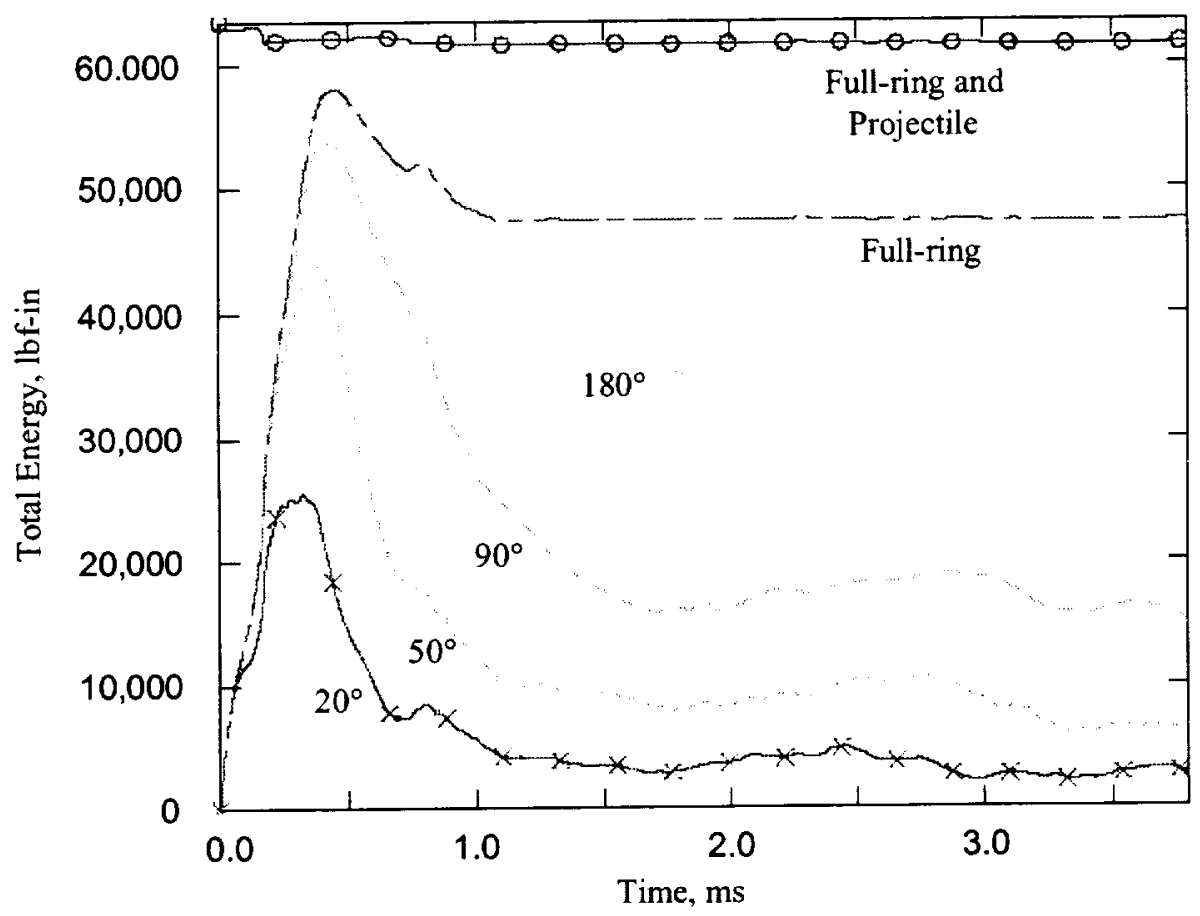

(b) Total energy in various arc sections centered on the point of impact

Figure 9. Finite element analysis results for a titanium disk projectile impacting full-ring composite structures at $600 \mathrm{ft} / \mathrm{s}$. Energy stored in arc sections centered on the point of impact is indicated for various arc angles. (a) Strain energy and (b) Total energy (strain energy + kinetic energy) 


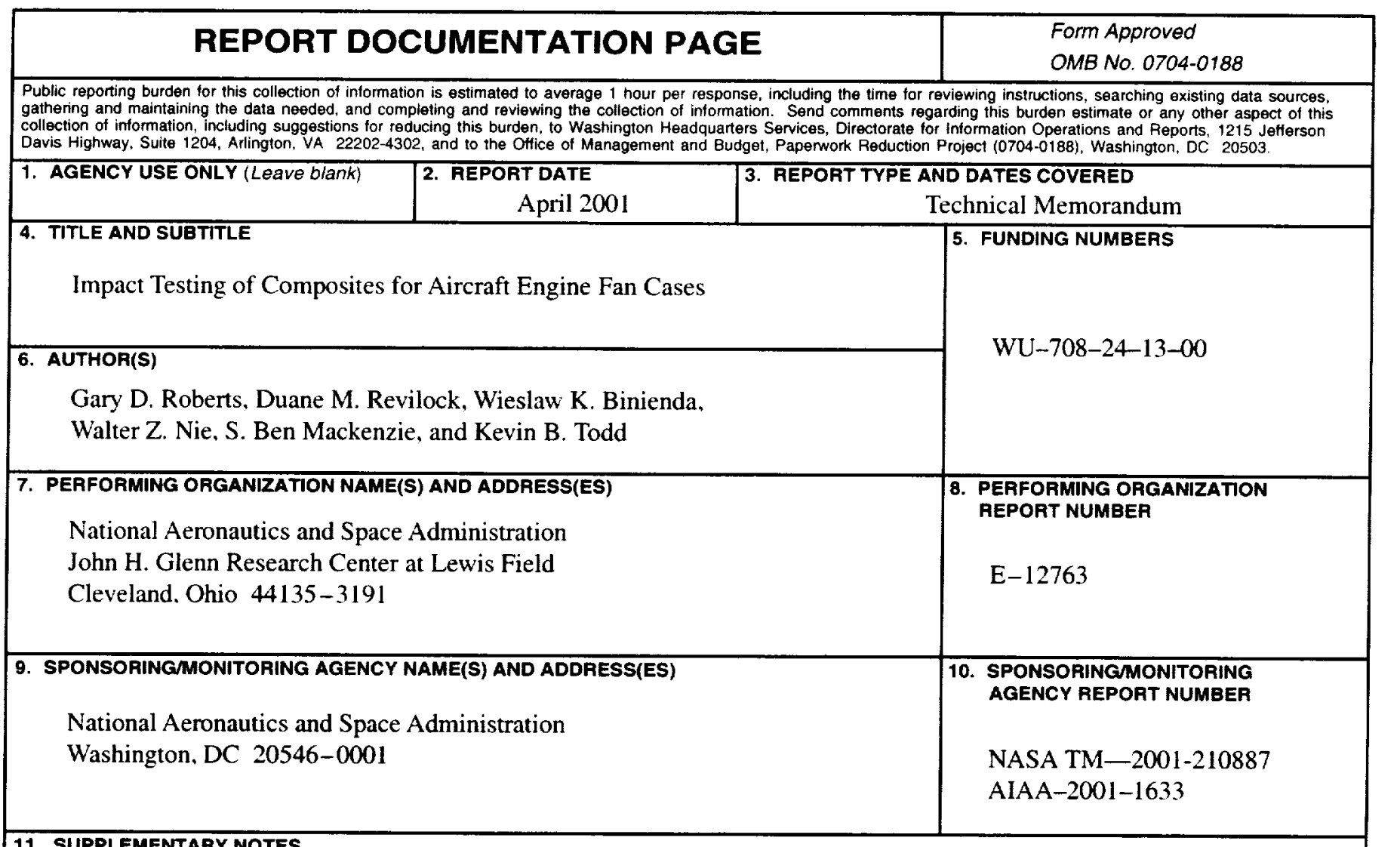

\section{SUPPLEMENTARY NOTES}

Prepared for the 42nd Structures, Structural Dynamics, and Materials Conference and Exhibit cosponsored by the AIAA, ASME, ASCE. AHS, and ACS. Seattle, Washington, April 16-19, 2001. Gary D. Roberts and Duane M. Revilock, NASA Glenn Research Center; Wieslaw K. Binienda and Walter Z. Nie, University of Akron, 302 Buchtel Mall, Akron, Ohio 44325-0001; S. Ben Mackenzie and Kevin B. Todd, Saint-Gobain Performance Plastics, Ravenna, Ohio (formerly Norton). Responsible person, Gary D. Roberts, organization code 5150, 216-433-3244.

\begin{tabular}{|l|l|l|l|l|}
\hline 12a. DISTAIBUTION/AVAILABILITY STATEMENT & 12b. DISTRIBUTION CODE
\end{tabular}

Unclassified - Unlimited

Subject Category: $24 \quad$ Distribution: Nonstandard

Available electronically at http://gltrs. grc.nasa.gov/GLTRS

This publication is available from the NASA Center for AeroSpace Information. 301-621-0390.

13. ABSTRACT (Maximum 200 words)

Before composite materials can be considered for use in the fan case of a commercial jet engine, the performance of a composite structure under blade-out loads needs to be demonstrated. The objective of this program is to develop an efficient test and analysis method for evaluating potential composite case concepts. Ballistic impact tests were performed on laminated glass/epoxy composites in order to identify potential failure modes and to provide data for analysis. Flat $7 \times 7$ in. panels were impacted with cylindrical titanium projectiles, and $15 \mathrm{in}$. diameter half-rings were impacted with wedge-shaped titanium projectiles. Composite failure involved local fiber fracture as well as tearing and delamination on a larger scale. A 36 in. diameter full-ring subcomponent was proposed for larger scale testing. Explicit, transient, finite element analyses were used to evaluate impact dynamics and subsequent global deformation for the proposed full-ring subcomponent test. Analyses on half-ring and quarter ring configurations indicated that less expensive smaller scale tests could be used to screen potential composite concepts when evaluation of local impact damage is the primary concern.

\section{SUBJECT TERMS}

Composites; Polymer matrix composites; Impact tests

15. NUMBER OF PAGES

17

16. PRICE CODE

\begin{tabular}{|c|c|}
\hline $\begin{array}{c}\text { 17. SECUAITY CLASSIFICATION } \\
\text { OF REPORT }\end{array}$ & $\begin{array}{c}\text { 18. SECURITY CLASSIFICATION } \\
\text { OF THIS PAGE } \\
\text { Unclassified }\end{array}$ \\
Unclassified \\
\hline
\end{tabular}

19. SECURITY CLASSIFICATION OF ABSTRACT

Unclassified
20. LIMITATION OF ABSTRACT

Standard Form 298 (Rev. 2-89)

Prescribed by ANSI Std. Z39-18 

- 
